\title{
O CONTROLE DA PROPORCIONALIDADE NA EXCLUSÃO DO SIMPLES NACIONAL POR DÉBITOS
}

\section{CONTROL PROPORTIONALITY THE EXCLUSION OF SIMPLE FOR NATIONAL DEBTS}

${ }^{1}$ Rafael Braga de Moura

\section{RESUMO}

O artigo ora proposto buscará analisar a exclusão das Microempresas e Empresa de Pequeno Porte do Simples Nacional por débitos. Será analisado a princípio o conceito econômico, jurídico e social da empresa, com a finalidade de demonstrar o significado da empresa, para entender a aplicação da função social desta. Noutro ponto, será tratado a exclusão da Microempresa e Empresa de Pequeno Porte, sob o aspecto da função social destas e a finalidade extrafiscal do Simples Nacional, sendo verificado, como ponto principal, a aplicação do princípio da proporcionalidade, sob a ótica dos controles da adequação e da necessidade, se estão sendo devidamente criados e interpretados, tanto pelo Poder Legislativo, quanto pelo Poder Judiciário.

Palavras-chave: Contencioso tributário, Extrafiscalidade, Função social, Proporcionalidade, Simples nacional, Micro e pequena empresa

\begin{abstract}
Article now proposed will seek to analyze the exclusion of Micro and Small Businesses of the National Simple by debts. It will be reviewed at first economic, legal and social concept of the company, in order to demonstrate the significance of the business to understand the application of the social function of this . Elsewhere, the exclusion will be treated in the Micro and Small Businesses, from the aspect of social function of these and extrafiscal purpose of the National Simple, being seen as the main point, that the principle of proportionality, from the viewpoint of controls appropriateness and necessity, whether they are being properly created and interpreted, both by the legislature, as by the judiciary .
\end{abstract}

Keywords: Tax litigation, Regulatory taxes, Social function, Proportionality, National simple, Small and medium enterprises

\footnotetext{
${ }^{1}$ Mestrando em Direito na Faculdades Milton Campos, FMC, Minas Gerais, MG(Brasil). Presidente da Comissão

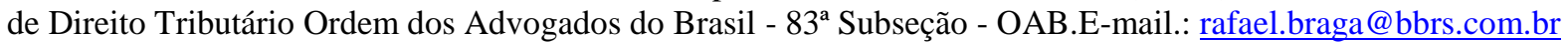




\section{INTRODUÇÃO}

Sabe-se que a finalidade do Sistema Tributário não é apenas arrecadatória de receitas para custear o Estado. Tal finalidade é a principal, porém, existem outras funções ao Direito Tributário que não somente a tributação para arrecadar receitas, também tem a finalidade de distribuir riqueza e de intervenção na ordem econômica e social, denominada hoje de extrafiscalidade.

O nosso problema teórico a ser estudado é a exclusão das Microempresas e das Empresas de Pequeno Porte por débitos no Simples Nacional, instituído pela Lei Complementar 123 de 2006, em seu artigo 17, inciso V, onde descreve que "Não poderão recolher os impostos e contribuições na forma do Simples Nacional a microempresa ou a empresa de pequeno porte que possua débito [...]”.

A Constituição Federal de 1988, em seu Capítulo I descreveu "Dos Princípios Gerais da Atividade Econômica" e logo em seu primeiro artigo (170) descreve que "A ordem econômica, fundada na valorização do trabalho humano e na livre iniciativa, tem por fim assegurar a todos existência digna, conforme os ditames da justiça social”, tal dispositivo observará os princípios nele constante, como o descrito no inciso III, que fala da "função social da propriedade", ou seja, o Estado deverá respeitar o Princípio da Função Social da Propriedade.

Fundado neste princípio, a Carta Magna, em seu artigo 179 também foi bem clara quanto à forma de tratamento dessas empresas pela União, os Estados, o Distrito Federal e os Municípios onde estes “deverão dispensar às Microempresas e às Empresas de Pequeno Porte, assim definidas em lei, tratamento jurídico diferenciado, visando a incentivá-las pela simplificação de suas obrigações [...] pela eliminação ou redução destas por meio de lei.”.

Assim, nos termos do artigo 146, inciso III, alínea 'd' da Constituição Federal de 1988 coube à Lei Complementar dispor sobre normas gerais para definir o tratamento diferenciado e favorecido para estas empresas.

A Lei Complementar 123 de 2006, conhecida como "Estatuto Nacional da Microempresa e da Empresa de Pequeno Porte", disciplinou a matéria, instituindo a arrecadação de forma simplificada, diferenciada e favorecida.

Uma das justificativas posta no Diário da Câmara dos Deputados no dia 03 de fevereiro de 2004, quando apresentada a proposta de Lei Complementar 123 de 2004 do então Deputado Juntahy Junior descreve que “[...] podemos perceber a importância das pequenas e 
microempresas no desenvolvimento de nossa economia e principalmente como fator de geração de emprego e distribuição de renda."2, ou seja, o objetivo era puramente extrafiscal, de intervenção do Estado no domínio econômico, com foco precípuo em distribuição de renda, geração de empregos e desenvolvimento da economia.

Desta forma, cremos que a finalidade da Constituição Federal em seus artigos bem como, a finalidade da Lei Complementar foi de fomentar estas empresas, trata-las de forma a estimular o seu crescimento com o objetivo de geração de emprego, distribuição de renda e desenvolvimento da economia. Pode-se perceber que conforme estudo do SEBRAE, estas empresas perfazem no ano de 2014 o total de $99 \%$ das empresas brasileiras, empregando com carteira assinada $52 \%$ da mão de obra, participam hoje com $27 \%$ do PIB, ou seja, são primordiais para a manutenção da economia do país.

Assim, podemos dizer que ao instituir a exclusão das empresas por dívidas do Simples Nacional, estaria o Estado atingindo diretamente a concorrência destas empresas, pois está diretamente ligada à capacidade contributiva, onde as Microempresas e Empresas de Pequeno Porte, em tese, com a mesma capacidade estariam sendo tratada de forma "desigual", isto porque, me parece que o objetivo dos dispositivos Constitucionais não foi o de arrecadar (finalidade fiscal), mas sim de fomentar estas empresas para distribuírem renda, gerarem emprego e desenvolverem a economia do Brasil. Por este motivo, estariam aplicando uma sanção política com o intuito meramente arrecadatório, deixando de lado a finalidade extrafiscal do Simples Nacional.

Por fim, torna-se imperioso, doravante, definir os critérios para aplicação dos controles do emprego de instrumentos tributários extrafiscais, especialmente no que diz respeito às exclusões das Micro e Pequenas Empresas do Simples Nacional. Neste caso, para o desenvolvimento do artigo será analisado e identificado os controles necessários para se ter o sopesamento de qual princípio deve ser aplicado. A execução do artigo demandará a apreciação das manifestações doutrinárias mais relevantes sobre o tema. Além disso, também pretende aprofundar na reflexão acerta dos critérios de controle das medidas tributárias extrafiscais, no caso, a proporcionalidade.

\footnotetext{
${ }^{2}$ JUNIOR, Juntahy. Projeto de Lei Complementar: Regulamenta o parágafo único do artigo 146 e o Incio IX do art. 170 da Constituição Federal e da outras providências. Disponível em :

http://www.camera.gov.br/sileg/integras/193056.pdf. Data de acesso: 23 de julho de 2015.
} 


\section{DO CONCEITO DE EMPRESA}

\subsection{CONCEITO ECONÔMICO DA EMPRESA}

Como nos outros códigos estrangeiros, no Brasil o legislador não se ocupou de definir de forma positiva o conceito de empresa, somente do empresário e descreveu as sociedades empresárias, por este motivo, se faz necessário à verificação por meio de entendimentos doutrinários.

A noção de empresa, no Brasil, advém do conceito da economia sobre empresa, ligada à ideia central de organização dos fatores, com objetivo de realização de uma atividade econômica.

\subsubsection{TEORIA NEOCLÁSSICA TRADICIONAL}

A visão microeconômica tradicional neoclássica da empresa surge em 1883 quando Marshall $^{3}$ descreveu a empresa como sendo “[...] um mero agente econômico de um determinado mercado, de caráter racional e maximizador." Este agente racional então, visa maximizar os seus lucros.

Walras ${ }^{4}$ em 1883 reafirmou o modelo de Marshall e acrescentou algumas teorias, como a teoria dos preços, onde os preços deveriam ser predefinidos, como em um leilão para que haja equilíbrio no mercado "os preços que permitem igualar oferta e demanda são previamente determinados e não existe incerteza em relação ao valor futuro das diferentes variáveis."

Já em 1920, Sraffa ${ }^{5}$ e Chamberlin ${ }^{6}$, discordando da teoria dos preços (concorrência perfeita), de Walras, pois, esta não era compatível com a realidade, posto que agentes econômicos não fossem influenciados apenas pelos preços, onde "o preço de um produto não é o único fator determinante da decisão de um consumidor, outros atributos como a qualidade e o prestígio de uma marca também expressão as preferências dos indivíduos."

Motivaram assim, um novo debate para redefinir o conceito e natureza de empresa, quando começou a segunda fase, onde a empresa era um instituto e também tinha que ter uma visão gerêncialista.

\footnotetext{
${ }^{3}$ MARSHALL, A. Princípios de economia: tratado introdutório. São Paulo: Abril, 1983.

${ }^{4}$ WALRAS, M. E. L. Compêndio dos elementos de economia política pura. São Paulo: Abril, 1983.
} 
Após a acepção econômica é que se torna possível a conceituação jurídica da empresa, interpretando e algumas vezes até importando o conceito econômico de empresa.

\subsubsection{Visão Institucional E Gerencialista Da Empresa}

A discussão da natureza da empresa continuou com Coase $^{7}$ em 1937, passando da ideia de que, a teoria tradicional de Marshall poderia ser aplicada, porém, as decisões de preços deveriam ser tomadas pelo empresário-coordenador, exercendo a função de leiloeiro descrito por Walras - no mercado, buscando na verdade não o preço em si, mas a redução dos custos, abrindo um debate da empresa como instituição, descrevendo que:

\footnotetext{
“à presente discussão está na suposição de que uma empresa deve ser interpretada não como um mero agente maximizador do mercado, mas como uma instituição que tem suas relações reguladas contratualmente, de tal modo que os custos de transação envolvidos sejam minimizados."
}

Porém, estes pensamentos de empresa como instituição, são criticados pela corrente gerêncialista, que tiveram como precursores Berlen \& Means em 1984, que após estudos nos Estados Unidos determinou que a nova forma de gerenciar a empresa era chamada de Moderna Sociedade Anônima.

Tendo o principal foco na separação entre gestão e propriedade das empresas. Descreve os autores que "enquanto a revolução industrial separou o trabalho do controle de seus instrumentos de produção, uma nova revolução, a das sociedades anônimas, separou e vem separando a propriedade do controle sobre os investimentos".

Assim, foram enfatizadas por estes e outros autores, nesta fase, novos critérios da empresa, que criticam a teoria tradicional, que era baseada nos preços, e enfatiza a concorrência baseada na qualidade e nos esforços de venda.

Buscou-se então a qualificação de pessoas que gerenciariam as empresas, para que estas sobrevivessem às mudanças do mercado, aos gostos dos consumidores, dentre outras coisas, o que nos levou à teoria gerêncialista da empresa, surgindo então a tecnoestrutura da empresa.

\footnotetext{
${ }^{5}$ SRAFFA, P. The laws of returns under competitive conditions. Economic Journal, Dec. 1926.

${ }^{6}$ CHAMBERLIN, E.H. The theory of monopolistic competition. Cambridge: Mass., 1933

${ }^{7}$ COASE, R.H. The nature of the firm. In: WILLIAMSON, O. E e WINTER, S.G. (Org.).The nature of the firm: origins, evolution, and development. Oxford: Oxford University Press, 1993.
} 


\title{
1.1.3. A TECNOESTRUTURA DA EMPRESA
}

Nesta fase, a crítica também é na teoria tradicional da empresa, desenvolvida por Marshall, dizendo Galbraith ${ }^{8}$ que esta teoria só se aplicava para “[...] propriedade individual, e que demandam baixo ou nenhum volume de capital, de tecnologia e dos complexos recursos organizacionais típicos das empresas modernas."

Galbraith $^{9}$ ainda argumenta que passou a existir à Sociedade Industrial Moderna, onde o mercado começaria a ficar somente com grandes concentrações de algumas grandes empresas, ajudando no controle de preços e sendo possível a instalação de tecnologias mais apuradas para melhorar as empresas, o que não é possível em muitas empresas pequenas e espalhadas.

Para o autor, o empresário tradicional é substituído por um grupo de pesoas, sendo que:

\begin{abstract}
“[...] na indústria moderna, grande número de decisões, e de todas as que sejam importantes, recorre a informações que são possuídas por mais de um homem. Tipicamente, recorre-se a conhecimento especializado científico e técnico, a informações acumuladas ou à experiência e ao senso artístico e intuitivo de muitas pessoas [...] Por conseguinte, a decisão na empresa moderna é produto não de indivíduos, porém de grupos." (GALBRAITH, 1984, p. 58-60). ${ }^{10}$
\end{abstract}

Entende o autor que o objetivo das empresas é o de alcançar um processo interno de crescimento e acumulação de capital, onde para isso, deve adotar estratégias para os consumidores e ter uma estrutura organizacional condizente com o mercado.

Assim, tem-se a evolução do conceito econômico de empresa, descrita por economistas de épocas diferentes, argumentando suas teorias e buscando aperfeiçoá-las.

Começasse por empresa com intuito de padronizar os preços, buscando um mercado perfeito, onde a procura e a demanda se exauriam, porém, com as críticas foi visto que este mercado é impossível de atingir, sendo necessário ter a empresa o controle do preço, de forma interna, se ajustando, diminuindo os custos, ou seja, gerenciando de forma correta.

Em seguida, percebermos que foi criada uma nova sistemática, onde as empresas deveriam na verdade ser gerenciadas de uma forma organizada, por mais de uma pessoa, juntando estruturas para diversificar produtos e ajustar-se às modificações do mercado. E entendemos que este é o praticado hoje pelas empresas, com, baixa dos custos em busca do

\footnotetext{
${ }^{8}$ GALBRAITH, J. K. O Novo Estado Industrial. São Paulo: Abril Cultural, 1984.

${ }^{9}$ Ob. Cit.

${ }^{10}$ Ob. Cit.
} 
aumento de capital, organização sistemática, diversificação de produtos para atendimento dos consumidores e gerenciamento por mais de um empresário.

Desta forma, após verificarmos os conceitos de empresa para a economia e estudarmos como as empresas estão se estruturando hoje, passaremos a estudar os conceitos jurídicos de empresa.

\subsection{CONCEITO JURÍDICO DA EMPRESA}

Sabemos que a empresa é organizada com a finalidade de atingir os consumidores, como descrito no conceito econômico. Muitos autores importam esse conceito e adotam como jurídico. Porém, alguns autores discordam desta forma de atribuir o conceito de empresa no ramo jurídico, preferindo a forma de tradução dos conceitos econômicos para os termos jurídicos.

Para Ulhoa Coelho" ${ }^{11}$ a empresa é uma atividade "[...] organizada com a finalidade de fazer circular ou produzir bens ou serviços".

Mamede $^{12}$, ao conceituar juridicamente a empresa descreve que:

“[...]é a organização de meios materiais e imateriais, incluindo pessoas e procedimentos, para a consecução de determinado objetivo (o objetivo social), com a finalidade genética de produzir vantagens econômicas que sejam aproveitáveis por seus titulares, ou seja, lucro que remunere aqueles que investiram na formação do seu capital empresarial"

Tomazette $^{13}$, também conceituou empresa, descrevendo que "empresa é atividade econômica organizada para a produção ou circulação de bens e serviços para o mercado".

Carvalho de Mendonça ${ }^{14}$, ao conceituar empresa, segue os preceitos de seu contemporâneo Cesare Vivante, quando diz que a empresa é:

[...] a organização técnico-econômica que se propõe a produzir mediante a combinação dos diversos elementos, natureza, trabalho e capital, bens ou serviços destinados à troca (venda), com esperança de realizar lucros, correndo os riscos por conta do empresário, isto é, daquele que reúne, coordena e dirige esses elementos sob a sua responsabilidade."

Pode-se perceber que existe um padrão nos conceitos, onde a empresa pratica atividade organizada, com a finalidade intermediária de produção ou circulação de bens e serviços. 
Porém, sabemos que não existe um conceito positivado, ou seja, nenhuma legislação descreveu o conceito de empresa, nem o Código Civil Italiano de 1942, nem o Código Civil Brasileiro de 2002, ambos se esquivaram em conceituar a empresa, descrevendo apenas sobre o empresário.

Assim, se torna extremamente desgastante e descritivo a explicação do conceito de empresa, sendo necessária - como foi feito - a transcrição de diversas teorias, se fazendo necessária a edição de uma norma transcrevendo o conceito de empresa para o meio jurídico, seja de forma a importar a do conceito econômico, seja em traduzir o conceito para o jurídico.

Estudado assim o conceito de empresa, mesmo sem exaurir as fontes, passaremos a verificar o conceito social da empresa, onde se tem alguns debates doutrinários, tendo em vista que a função social da empresa é um conceito aberto, sendo interpretado da forma que melhor convier ao intérprete.

Desta forma, podemos dizer que um conceito que seria pelo menos consensual da empresa seria organizada com finalidade de produzir ou circular bens e serviços para o mercado, sob a responsabilidade do empresário, com intuito de lucro.

\subsection{CONCEITO SOCIAL DA EMPRESA}

Para que seja possível falarmos sobre o conceito social da empresa, se faz necessário abordarmos a evolução histórica para se formar a Constituição Federal de 1988, onde prevê em dois capítulos diferentes a "Da Ordem Econômica e Financeira" e "Da Ordem Social”.

A evolução se deu com a Revolução Francesa que aconteceu nos anos de 1789 1799. A primeira grande vitória da revolução foi quando em 1789 foi aprovado a Declaração dos Direitos do Homem e do Cidadão, onde foram criados então os primeiros direitos fundamentais, chamados pela doutrina de direitos fundamentais de primeira dimensão, sendo eles: Direito à vida; à liberdade; à propriedade; à igualdade perante a lei; ao devido processo legal.

\footnotetext{
${ }^{11}$ COELHO, Fábio Ulhoa. Curso de Direito Comercial. $18^{a}$ Edição. São Paulo: Saraiva, 2014. V. 1.

${ }^{12}$ MAMEDE, Gladston. Direito empresarial brasileiro: teoria geral dos contratos. 1. Ed. São Paulo: Atlas. 2010, v.5

${ }^{13}$ TOMAZETTE, Marlon. Curso de Direito Empresarial - Títulos de Crédito. Vol. 2, $3^{\text {a }}$ edição

${ }^{14}$ José Xavier Carvalho de Mendonça ; atualizado por Ricardo Rodrigues da Gama. Tratado de direito comercial brasileiro. Imprenta: Campina, SP, Russell, 2003.
} 
A segunda fase da evolução se deu com a Revolução Industrial, onde a burguesia buscava se firmar no senário utilizando o trabalho do homem pelo homem, começa-se então a chamada, classe proletária e a exigência desacerbada aos trabalhadores, que laboravam diariamente, sem nenhum direito. Nesta época, os proletariados, apoiados por filósofospolíticos da época, como Karl Marx, que criaram ideais para o levante dos proletários, exigiram do Estado uma intervenção protecionista, sendo criados então, na época, os direitos fundamentais, chamados de segunda dimensão, tais direitos não substituíram os de primeira dimensão, apenas complementaram aqueles.

São direitos fundamentais de segunda dimensão o: Direito à assistência social; ordem econômica; saúde; educação; igualdade material e não meramente formal; ao trabalho.

Tais direitos foram firmados na Constituição Mexicana (1917) e Constituição de Weimar (1919), onde constaram os primeiros direitos fundamentais da época, começando então uma nova era constitucional.

No Brasil, a primeira Constituição a prever a ordem financeira e social foi a de 1934, que foi dividia em 1988, passando a ser "Da Ordem Econômica e Financeira" e "Da Ordem Social”, garantindo assim a todos, os direitos fundamentais de primeira e segunda dimensão, onde se buscaria pelo trabalho e a livre iniciativa o bem-estar social de todos com o objetivo maior de se garantir a dignidade da pessoa humana, uma forma de justiça social.

Nesta Constituição Federal, de 1988, os conceitos econômicos e sociais - que garantem os direitos fundamentais por meio do Estado, que busca contribuição de todos estão previstos nos artigo 170 e 183.

O mestre Afonso da Silva ${ }^{15}$ descreve que a empresa, tem um fim e deve cumprir o mesmo, quando diz que a Constituição "não estava simplesmente preordenando fundamentos às limitações, obrigações e ônus relativamente à propriedade privada, princípio também da ordem econômica e, sujeita, só por si ao cumprimento daquele fim."

Collado $^{16}$ justifica que a justiça social "introduziu, na esfera interna do direito de propriedade, um interesse que pode não coincidir com o do proprietário e que, em todo caso, é estranho ao mesmo."

Acrescentando ao conceito social da empresa, Comparato $^{17}$, descreve que:

“[...] a função social da propriedade não se confunde com as restrições legais ao uso e gozo dos bens próprios; em se tratando de bens de produção, o poder-dever do proprietário de dar à coisa uma destinação compatível com o interesse da coletividade transmuda-se, quando tais bens são incorporados a uma exploração empresarial, em poder-dever do titular do controle de dirigir a empresa para a realização dos interesses coletivos" 
Assim, a empresa tem sua função social, prevista na Constituição Federal, bem como em outas leis, sendo que nestas outras leis, como ambiental, trabalhista, existem penalidades por descumprimento desta chamada "função social".

\title{
2. DA FUNÇÃO SOCIAL DA EMPRESA
}

Os preceitos constitucionais são claros ao distinguirem a proteção da propriedade como também a proteção da empresa, posto que não fazem qualquer especificação sobre qual propriedade recaem, nas palavras de Petter $^{18}$ "[...]na medida em que a propriedade, segundo o dispositivo em comento, deve atender à função social, e não tendo havido distinção entre qualquer espécie de propriedade, por certo aqui se inclui a propriedade empresária."

O legislador constituinte que definirá as principais e mais importantes matérias, sendo a Constituição Federal, hierarquicamente, superior a qualquer outra norma. Em outras palavras, se faz necessário que a Constituição Federal preveja as matérias que sejam de maior relevância, para que possa embasar as normas hierarquicamente inferiores, devendo estas respeitarem as diretrizes da norma maior, Perez $^{19}$ ilustra bem a presente passagem, dizendo que:

\begin{abstract}
A partir do momento em que se assentou a idéia de constituição como norma, dota de eficácia e condicionadora de todo o ordenamento jurídico, que lhe é hierarquicamente inferior, parece lógico que a unidade e segurança do sistema demanda que a definição de tais interesses deva ser explorada em seu texto. Os 'interesses maiores da sociedade' devem corresponder, assim, às escolhas democráticas do legislador constituinte.
\end{abstract}

A função social da empresa segue princípios norteadores da Ordem Econômica do Estado brasileiro, tais princípios que irão dar a direção a ser tomada pela empresa e pelo legislador, segundo Amaral ${ }^{20}$ "[...] o entendimento da função social da propriedade e, por conseguinte, da empresa, há de ser encarado com base nos demais princípios colocados em nossa Lei Maior como norteadores da Ordem Econômica do Estado brasileiro."

\footnotetext{
${ }^{15}$ SILVA, José Afonso da. Curso de Direito Constitucional positivo. 31.ed. rev. e atual. São Paulo: Malheiros, 2008, p. 282

${ }^{16}$ COLLADO, Pedro Escribano. Legislacion administrativa: parte general. 19 ed. Universidad de Sevilla. Servicio de Publicaciones, 2003.

${ }^{17}$ COMPARATO, Fábio Konder . Aspectos Jurídicos da Micro-Empresa. SAO PAULO: REVISTA DOS TRIBUNAIS, 1970.

${ }^{18}$ PETTER, Lafayete Josué. Princípios constitucionais da ordem econômica: o significado e o alcance do art. 170 da constituição federal. São Paulo: RT, 2005, p.217

${ }^{19}$ PEREZ, Viviane. Função social da empresa: uma proposta de sistematização do conceito.2004, p.2

${ }^{20}$ AMARAL, Luiz Fernando de Camargo Prudente do. A função social da empresa no direito constitucional econômico brasileiro. São Paulo: SRS Editora, 2008, p. 117.
} 
Conforme previsto no Artigo 170 da Constituição Federal, que trata dos princípios da Ordem Econômica do Estado brasileiro pode-se dizer que todos devem ter a mesma importância, porém, existirão princípios que se amoldaram em casos concretos melhor do que os demais.

A transcrição do referido preceito não só demonstra a preocupação do constituinte com a construção de uma sociedade justa e igualitária, como traz à baila o fato de que, ao serem previstos diversos princípios aplicáveis a Ordem Econômica, cada um deles deverá ter a mesma importância, mas poderá se moldar mais adequadamente à determinado caso concreto. $^{21}$

Destaca-se por fim que a empresa, tem grande relevância e importância no Estado, não só social, e visando isso, o Artigo 170 da Constituição Federal de 1988 prevê todos os fatores pertinentes à atividade econômica, sendo que pode-se destacar que o exercício da empresa será a principal, posto que somente com o funcionamento regular desta, poderá os demais princípios constitucionais serem cumpridos, "[...]assim, o que vemos, em verdade, no artigo 170 da Constituição Federal é a tradução de todos os fatores a serem observados na consecução de atividade econômicas, sendo a principal delas aquela que se dá como exercício da empresa." 22

\section{A EXTRAFISCALIDADE DO SIMPLES NACIONAL}

A princípio cumpre destacar nas palavras de Paulo de Barros Carvalho ${ }^{23}$ que, "[...] o Direito Tributário somente se ocuparia de uma parcela de um destes polos: a obtenção de receitas através de tributos.", ou seja, o objetivo principal do Direito Tributário é do de arrecadar, este é o responsável por providenciar recursos para a atuação estatal.

Ocorre que o Direito Tributário também tem outras tarefas, a de proteção dos valores constitucionais, agindo como instrumentos diretos e imediatos. Faz-se necessário a intervenção no domínio econômico para coibir atitudes que contrariam a Constituição Federal

\footnotetext{
${ }^{21}$ Ob. Cit., p, 121.

22 Ob. Cit., p, 122.

${ }^{23}$ CARVALHO, Paulo de Barros. Curso de Direito Tributário. 19 ed. São Paulo: Saraiva, 2007.
} 
ou até mesmo incentivar condutas, buscando sempre atingir a finalidade constitucional, conforme ensina Eros Grau ${ }^{24}$

Direito Tributário [...] nem sempre se destinam exclusivamente à tarefa de prover recursos aos cofres públicos, mas também podem servir como instrumentos diretos e imediatos para a proteção de vens jurídicos ou concreção de valores constitucionais. [...] se prestam como meio para incentivar ou coibir condutas por parte de seus destinatários, comportamento estes que contribuem para a realização ou realizam per se - finalidades resguardadas pela Constituição Federal.

Desta forma, como a finalidade do Direito Tributário também será o de proteção dos valores constitucionais, no intuito de coibir ou incentivar certas condutas, surgem às normas tributárias indutoras e as normas de simplificação. ${ }^{25}$

Pode-se dizer que a extrafiscalidade se configura com as imposições sou exonerações e normas indutoras de incentivo ou desincentivo de certa conduta, com intuito de cumprimento de finalidades constitucionais.

[...] quando estas mesmas imposições ou exonerações são empregadas para incentivar ou coibir condutas que promovem a "efetivação concreta de desidérios constitucionais", com efeitos imediatos nos mais diversos setores da sociedade, configura-se a extrafiscalidade ou a busca pela concretização de fins extrafiscais. ${ }^{26}$

A doutrina clássica distingue os tributos extrafiscais e fiscais pela sua destinação.

Extrafiscalidade é o emprêgo dos instrumentos tributários - evidentemente, por que os tem à disposição - como objetivos não fiscais, mas ordinatórios. É, com efeito, notável que a tributação exerce influências instigantes ou depressivas, na economia em geral. Não existem e não parecem existir as sonhadas finanças neutras [...] Ainda que inconscientemente, o legislador, ao manejar o instrumento fiscal, age sôbre a economia, nela provocando reflexos positivos ou negativos. Tal caráter é inerente ao tributo, não sendo mesmo possível imaginá-lo sem êle. Não é, entretanto, a isto que se pretende aludir, quando se fala em extrafiscalidade. $O$ que se intenta designar, sob tal nome - como dito - é o emprêgo deliberado do instrumento tributário para finalidades não financeiras, mas regulatórios de comportamentos sociais, em matéria econômica, social e política. É o fenômeno observado por THEOTÔNIO MONTEIRO DE BARROS quando doutrina que "quando lança e arrecada tributos, o Estado me sempre tem em vista os mesmos fins. Ora busca pura e simplesmente a obtenção de meios pecuniários destinados a coibir suas despesas; ora êsse objetivo assume um caráter secundário, figurando em plano principal uma finalidade social

${ }^{24}$ GRAU, Eros. A rodem econômica na constituição de 1988. São Paulo: Malheiros, 1998, p.156-159

${ }^{25}$ SHOUERI, Luis Eduardo. Normas Tributárias Indutoras e Intervenção no Domínio Econômico. Rio de Janeiro: Forense, 2005.

${ }^{26}$ GOUVÊA, Marcus de Freitas. A extrafiscalidade no Direito Tributário. Belo Horizonte: Del Rey, 2006, p.47 
ou política." Quer dizer, quando se trata de extrafiscalidade o legislador não só se despreocupa da receita decorrente do tributo, como quer que ela não se realize. ${ }^{27}$

Como pode-se perceber, quando o legislador cria o tributo extrafiscal, não tem se quer preocupação de obter receitas, mas sim, de incentivar ou desincentivar condutas, como no caso principal que se discute, onde o legislador constituinte instituiu tratamento diferenciado e simplificado às Micro e Pequenas Empresas, com intuito de incentivá-las ao desenvolvimento para geração de renda e empregos, porém, com a sua exclusão por questões eminentemente fiscais, ou seja, arrecadação de tributos, deixou-se de lado as finalidades extrafiscais de incentivo, diga-se, ainda mais em momento de crise da empresa e passou-se a ter uma visão arrecadatória dos tributos devidos, sob pena de exclusão do Simples Nacional.

Neste mesmo sentido, Nabais ${ }^{28}$ afirma que:

A extrafiscalidade traduz-se no conjunto de normas que, embora formalmente integrem o direto fiscal, tem por finalidade principal ou dominante a consecução de determinados resultados económicos ou sociais através da utilização do instrumento fiscal e não a obtenção de recitas para fazer face às despesas públicas. Trata-se assim de normas (fiscais) que, ao preverem uma tributação, isto é, uma abalação ou amputação pecuniária (impostos), ou uma não tributação ou uma tributação menor à requerida pelo critério da capacidade contributiva, isto é, uma renúncia total ou parcial a essa abalação ou amputação (benefícios ficais), estão denominados pelo instituto de actuar directamente sobre os comportamentos económicos e sociais dos destinatários, desincentivando-os, neutralizando-os nos seus efeitos económicos e sociais ou fomentando-os, ou seja, de normas que contêm medidas de política económica ou social

Mais atualmente, a distinção entre fiscalidade e extrafiscalidade se encontra nos efeitos que tais medidas causam, tendo ou não finalidade arrecadatória. Neste ponto, a questão do Simples Nacional se realça ainda mais, posto que, tal medida tem finalidade também arrecadatória, posto que, deve a Micro e Pequena Empresa pagar os tributos, porém, os efeitos principais da medida, ou seja, o que motivou a criação do regime simplificado e do Simples Nacional, foi o objetivo constitucional de proteção destas empresas, com viés de incentivá-las para que fosse possível competir com outas empresas, sendo estas necessárias para a continuidade do Estado.

[...] mais modernamente, já um novo enfoque para a distinção proposta, que encontra fundamento não mais na finalidade perseguida através dos instrumentos tributários, mas nos efeitos por eles causados. Independentemente de se prestar à consecução de uma finalidade não-arrecadatória, a medida tributária soemnte seria classificada como extrafiscal na hipótese de causar efeitos preponderantemente nãoarrecadatórios. $^{29}$

\footnotetext{
${ }^{27}$ ATALIB A, Geraldo. Sistema Constitucional Tributário Brasileiro. São Paulo: Revista dos Tribunais, 1966, p. $150-151$

${ }^{28}$ NAB AIS, José Casalta. O dever Fundamental de Pagar Impostos. Coimbra: Almedina, 2004, p. 629
} 
Em sabias palavras Schoueri ${ }^{30}$ descreve que "no lugar de identificarem-se normas tributárias indutoras por sua finalidade, estuda-se o efeito indutor das normas tributárias"

Desta forma, temos que vale-se mais os efeitos das normas do que a sua finalidade, desta forma, o Simples Nacional tem como efeito o incentivo às Micro e Pequenas Empresas, não podendo este instituto com efeitos de incentivos às empresas que precisam crescer, exclui-las por débitos, o que em tese, seria normal de se acontecer com qualquer empresa, ainda mais em empresas pequenas, ademais, este foi o real objetivo da Constituição Federal.

anto os critérios tradicionais, como os critérios mais atuais, se completam, não tendo conotação excludente um do outro, posto que "serão considerados extrafiscais os instrumentos tributários marcados fortemente por uma finalidade não-arrecadatória ou , ainda, aqueles cujos efeitos preponderantes qualifiquem-se como não-arrecadatórios." ${ }^{\text {31 }}$

\section{DO CONTROLE DA PROPORCIONALIDADE}

\subsection{CONTROLE DE ADEQUAÇÃO}

Sabe-se que a aplicação da extrafiscalidade, depende da aplicação da proporcionalidade, ou seja, é necessário que se verifique se à medida que está sendo adotada é proporcional com a sua finalidade, conforme destaca Ávila, serve como instrumento "estruturador de aplicação de princípios que concretamente se imbricam em torno de uma relação de causalidade entre o meio e um fim". ${ }^{32}$

Para que se possa verificar a aplicação da proporcionalidade, é necessário envolver o controle de adequação e depois, o controle de necessidade, $\operatorname{Barros}^{33} \operatorname{argumenta~que:~}^{3}$

\footnotetext{
${ }^{29}$ PAPADOPOL, Marcel Davidman. A extrafiscalidade e os controles de proporcionalidade e de igualdade. Porto Alegre: Universidade do Rui Grande do Sul - UFRS, 2009, p.19.

${ }^{30}$ SHOUERI, Luis Eduardo. Normas Tributárias Indutoras e Intervenção no Domínio Econômico. Rio de Janeiro: Forense, 2005, p.29

${ }^{31}$ PAPADOPOL, Marcel Davidman. A extrafiscalidade e os controles de proporcionalidade e de igualdade. Porto Alegre: Universidade do Rui Grande do Sul - UFRS, 2009, p.20.

${ }^{32}$ ÁVILA, Humberto. Teoria dos princípios: da definição à aplicação dos princípios jurídicos. $8^{\mathrm{a}}$ ed. São Paulo: Malheiros, 2008: 162.

${ }^{33}$ BARROS, Suzana de Toledo. O princípio da proporcionalidade e o controle de constitucionalidade das leis restritivas de direitos fundamentais. Brasilia: Brasília jurídica, 2003: 48-50.
} 
“[...] aplicação do postulado da proporcionalidade envolve um controle de adequação, que segundo a jurisprudência do Tribunal Constitucional Alemão, implicaria avaliar se a medida possui potencial relação de causalidade em face de uma ou mais finalidades resguardadas pelo ordenamento jurídico".

A finalidade da norma extrafiscal dependerá da analise de uma ou mais finalidades resguardadas no ordenamento jurídico, desta forma, com a aplicação da proteção da empresa, tratamento diferenciado e favorecido às Microempresas e às Empresas de Pequeno Porte e ainda à concorrência (146-A da Constituição Federal de 1988) tem-se que a exclusão não atinge a finalidade da norma.

Assim, é imprescindível verificar se as medidas extrafiscais estão sendo atingidas, caso contrário, estas seriam inválidas, sendo que "somente se reputaria válidas as medidas tributárias extrafiscais capazes de conduzir ao resultado almejado",34

Deve-se definir como este controle de adequação será feito, onde segundo Ávila ${ }^{35}$ “[...]deve-se estabelecer quando um meio conduz à realização de um fim”, a medida deve ter uma relação entre o meio (porque foi feita) e o fim (qual o seu objetivo) para caracterizar o seu controle de adequação, e continua Ávila ${ }^{36}$ dizendo que:

"[...] a relação de pertinência entre um meio e o fim pode ser examinada em diferentes aspectos: um meio pode ser adequado à realização de um fim em termos quantitativos (intensidade), qualitativos (qualidade) ou probabilísticos (certeza). Com efeito, é necessário definir se o legislador deve escolher o meio tributário 'mais intenso, o melhor e o mais seguro para atingir o fim, ou tem o dever de escolher um meio que "simplesmente" promova o fim' almejado"

O ente público deve indicar os motivos das medidas extrafiscais para que seja possível ao Poder Judiciário julgar se estas atendem as finalidades propostas e se estas finalidades estão em conformidade com o ordenamento jurídico, conforme explica Papadopol ${ }^{37}$

"A finalidade perseguida por meio das medidas tributárias extrafiscais deve ser indicada pelo próprio ente público e o controle de adequação deve ser exercido pelo Poder Judiciário nos estritos limites da finalidade em questão, dispensando-se a necessidade de exercício de imaginação em sede de controle jurisprudencial"

\subsection{CONTROLE DE NECESSIDADE}

\footnotetext{
34 ÁVILA, Humberto; PAPADOPOL, Marcel. Fundamentos do Direito Tributário. Marcial Pons, São Paulo, p. $278,2012$.

${ }^{35}$ Ávila, Humberto. Teoria dos princípios: da definição à aplicação dos princípios jurídicos. 8.ed. São Paulo: Malheiros, 2008: 165.

${ }^{36}$ Ob. Cit., p. 165.

${ }^{37}$ Ob. Cit., p. 281.
} 
Além do controle de adequação, também se faz necessário verificar o controle de necessidade, sendo esta capaz de concluir se a medida adotada pelo ente público é realmente necessária e ainda, se estão em conformidades com os princípios jurídicos ou direitos fundamentais, Papadopol descreve que "O controle de necessidade impõe ao interprete o dever de verificar a existência de maios alternativos à consecução da finalidade extrafiscal, mas que, em contrapartida, não inibiam a realização de outros princípios jurídicos ou direitos fundamentais dos contribuintes". 38

Neste ponto, podemos dizer que os princípios jurídicos devem ser respeitados por seu grau de importância na eficácia e restrição, devendo ser comparado aos demais valores que outros princípios proporcionam ao tema, Papadopol argumenta sobre o assunto que:

\section{“[...] a comparação ente os diversos meios colocados à disposição do Poder Público para a realização das finalidades prestigiadas pelos princípios jurídicos demanda a comparação entre o grau de eficácia de cada uma delas e o grau de restrição que propiciam aos demais valores reconhecidos por outros princípios jurídicos". 39}

Desta forma, deve-se ter uma ponderação de princípios, onde deverá ser verificada a finalidade da norma para saber qual princípio será mais relevante do que o outro, conforme explica Lorenz ${ }^{40}$ quando diz que "existem princípios jurídicos que se reputam mais relevantes ao ordenamento jurídico do que outros”. Dentre os princípios, pode-se dizer que existem os mais importantes como os princípios fundamentais e os menos importantes, como os setoriais. $^{41}$

O controle de necessidade tem que ser ponderado também pela aplicação dos princípios jurídicos, onde será verificado qual princípio será mais condizente com a finalidade da norma, conforme descreve Papadopol ${ }^{42}$ que, "a prevalência abstrata de um princípio jurídico sobre outro - denominada, ordinariamente, de precedência axiológica e estabelecida pelo postulado de ponderação - causa relevante impacto sobre o controle de necessidade."

\footnotetext{
${ }^{38} \mathrm{Ob}$, cit., p.281.

${ }^{39} \mathrm{Ob}$, cit., p. 281.

${ }^{40}$ LARENZ, Karl. Metodologia da ciência do direito. Lisboa: Fundação Calouste Gulbenkian, 1997: 575; NOVAIS, Jorge Reis. Direitos fundamentais: trunfos contra a maioria. Coimbra: Coimbra Ed., 2006: 95; MAIOR BORGES, Jorge Souto. <Pro-dogmática: por uma hierarquização dos princípios constitucionais>. Revista Trimestral de Direito Público, 1/141-146.

${ }^{41}$ MAIOR BORGES, Jorge Souto. <Pro-dogmática: por uma hierarquização dos princípios constitucionais>. Revista Trimestral de Direito Público, 1/146.

42 ÁVILA, Humberto; PAPADOPOL, Marcel. Fundamentos do Direito Tributário. Marcial Pons, São Paulo, p. $282,2012$.
} 
Assim, os princípios fundamentais, prevalecem sobre os setoriais, sendo que dizem que os princípios fundamentais não podem ser alterados nem por emenda constitucional, já os setoriais são mais toleráveis.

Pode-se dizer que é claro a contrariedade do artigo que permite a exclusão da Microempresa e da Empresa de Pequeno Porte do Simples Nacional por dívidas, posto que tal dispositivo não coadune com a finalidade da norma de extrafiscalidade, que é a de fomentar o pequeno empresário, permitindo que este possa gerar empregos, distribuir renda e contribuir para o crescimento do país, bem como, não cumpre com os princípios fundamentais e nem setoriais presente nos caso, como a igualdade, capacidade contributiva, proporcionalidade, proteção da empresa, dentre muitos outros que fundam o Simples Nacional.

Nas palavras de Ávila ${ }^{43}$, "[...]somente nos casos ditos evidentes seria possível a declaração da nulidade do meio eleito pelo Poder Público através do exercício do controle de necessidade", assim, creio que estamos diante de um caso evidente de nulidade do dispositivo que permite a exclusão da empresa no Simples Nacional por dívidas.

Além disso, também descreve Papadopol ${ }^{44}$ que "[...] as medidas adotadas pelo Poder Público mais restringe a realização de finalidades constitucionais do que as fomenta.". O poder público ao invés de fomentar, cumprindo normas constitucionais, acaba por restringindo com medidas que não vão atingir a finalidade da norma e deixa assim de fomentar.

Pode-se dizer que o controle de necessidade será mais flexível à analise do judiciário do que o controle de adequação, posto que este último tratará da finalidade da norma, ou seja, se esta sendo atingida, o controle está feito, mas o último, englobará outras analises mais aprofundadas, “[...]apesar de também se caracterizar como um controle de inequivocidade ou evidência $^{45}$, permite uma maior extensão e intensidade da avaliação que será promovida pelo Poder Judiciário do que aquela permitida no campo da adequação."46

Temos então que a proporcionalidade demandaria um contorno de averiguações para o seu controle, como a sua adequação, respeitando o meio para se atingir o fim, bem como, a sua necessidade, onde se teria que averiguar se esta é realmente necessária e se cumpre os

\footnotetext{
43 ÁVILA, Humberto. Teoria dos princípios: da definição à aplicação dos princípios jurídicos. 8 ed. São Paulo: Malheiros, 2008: 169-170

${ }^{44}$ Ob. Cit., p. 284.
} 
limites de princípios e direitos fundamentais, nas palavra de Barcellos ${ }^{47}$, "a amplitude deste controle será maior: a) quanto maior a restrição aos princípios contrapostos; b) quanto mais relevante(s) for(em) a(s) finalidade(s) afetada(s) pela medida tributária extrafiscal; c) quanto mais particularizada for a medida tributária extrafiscal."

Tem-se um controle com relação aos critérios da norma, sendo que quanto mais abrangentes estas forem, menos será a interferência, e quanto mais princípios afetarem, maior será a sua exigência de controle, sendo o "controle de necessidade menos amplo e aprofundado quanto mais técnica for à decisão de adoção da medida tributária extrafiscal e quanto mais duvidoso o resultado futuro"

\section{CONCLUSÃO}

Sabe-se que os julgados sobre o tema da extrafiscalidade no Brasil são recentes. Porém, as questões tributárias - especialmente as questões de extrafiscalidade - evoluíram bastante, chegando no ponto atual que não se pode argumentar a discricionariedade do Estado para aplica-las, sob o argumento de que escaparia ao controle do Poder Judiciário apreciar tais matérias, por este motivo, se faz necessário o estudo do caso em que o Supremo Tribunal Federal declarou constitucional a exclusão das Micro e Pequenas Empresas do Simples Nacional.

Os direitos fundamentais prescritos na Constituição Federal devem ser respeitados pelo Estado, sendo o estado representado pelo Poder Executivo, que o representa para gerir e regular todas as variáveis possíveis, dentre elas, a tributação.

Temos que buscar analisar a Constituição Federal com um texto jurídico, embasando todos os conceitos jurídicos do nosso ordenamento, se tratarmos esta apenas como um texto acessório, estaremos deixando de dar a devida importância para esta carta.

\footnotetext{
${ }^{45}$ Recorda-se que, por controle de evidência, quer-se afirmar que somente deve haver a anulação do meio equiparando manifestamente pior do que seu paradigma.

${ }_{46}$ ÁVILA, Humberto; PAPDOPOL, Marcel. Fundamentos do Direito Tributário. Marcial Pons, São Paulo, p. $285,2012$.

${ }^{47}$ BARCELLOS, Ana Paula de. Ponderação racionalidade e atividade jurisprudencial. Rio de Janeiro: Renovar, 2005:85.

48 ÁVILA, Humberto. Teoria dos princípios: da definição à aplicação dos princípios jurídicos. 8 ed. São Paulo: Malheiros, 2008: 174-175) (p. 283/284
} 
Neste pensamento, de pensar a Constituição como um todo, podemos nos deparar com o julgamento do Supremo Tribunal Federal ${ }^{49}$ onde foi julgada a constitucionalidade da medida de exclusão da Micro e Pequena Empresa do Simples Nacional, informando a princípio que trata-se de "um regime especial de tributação de caráter opcional por parte dos contribuintes" $^{, 50}$ e ainda, argumenta que caso estas empresas, que representa 97,5\% das empresas no Brasil, deixassem de pagar os tributos, acarretaria o colapso do microssistema de tributação (Simples Nacional).

Sobre tal pensamento, a princípio, se faz necessário analisarmos as aplicações da fiscalidade e extrafiscalidade sobre o tema. É certo que toda a medida extrafiscal, também tem um viés arrecadatório, porém, para que a medida seja extrafiscal, como já analisado, tem-se que verificar a finalidade ${ }^{51}$ e o seus efeitos ${ }^{52}$.

No campo da finalidade, entendimento mais tradicional da norma tributária, tem-se que a finalidade da norma tem que ser não-arrecadatória para se caracterizar a extrafiscalidade, sendo que no presente caso, a finalidade da norma deve ser, conforme preceitua a Constituição Federal de 1988, nos artigos 170, inciso IX, 179 que tais empresas devem ser tratadas de forma desigual, diferente e simples, e que tal tratamento é dever a ser observado por todos os entes da federação. Além disso, também disciplinou a Carta

Republicana que deveria a Lei Complementar tratar das normas gerais ao tratamento diferenciado, favorecido e simplificado destas Micro e Pequenas Empresas, nota-se que o objetivo principal da norma é a forma de tratamento mais favorecido para estas empresas, não tendo como finalidade a arrecadação de tributos, como nos casos de instituição de norma com finalidade arrecadatória, como o Imposto de Renda.

\footnotetext{
${ }^{49}$ BRASIL. Supremo Tribunal Federal. Recurso Extraordinário $n^{\circ}$ 627.543. Relator(a): Dias Tofolli. Acórdão em 29.10.2014, DJ 14.11.2013 (Ata n 29) DJE 226. Disponível em: http://www.stf.jus.br. Acesso em: 13 de agosto de 2015.

${ }^{50}$ Ob. Cit., p. 6

${ }^{51}$ Sobre o assunto: NABAIS, José Casalta. O dever Fundamental de Pagar Impostos. Coimba: Almedina, 2004, p. 629 e ATALIBA, Geraldo. Sistema Constitucional Tributário Brasileiro. São Pauulo: REvista dos Tribunais, 1966, p. 150-151.

${ }^{52}$ Sobre o assunto: SCHOUERI, Luis Eduardo. Normas Tributárias Indutoras e Intervenção no Domínio Econômico. Rio de Janeiro: Forense, 2005, p.29 e PAPADOPOL, Marcel Davidman. A extrafiscalidade e os controles de proporcionalidade e de igualdade .Porto Alegre: Universidade do Rui Grande do Sul - UFRS, 2009.
} 
Assim, quanto a questão de finalidade, com facilidade se percebe que tal finalidade não foi o de arrecadar mais com o tratamento, pelo contrário, arrecadaria-se menos para que tais empresas pudessem competir no mercado, viabilizando o que estão fazendo, ou seja, gerando empregos, distribuindo renda e participando com uma porcentagem considerável no Produto Interno Bruto brasileiro.

No que tange ao ponto dos efeitos, trazido pela parte mais atual dos doutrinadores, conforme já citado no presente artigo, podemos perceber que o Simples Nacional tem o efeito de incentivar condutas, mesmo que de forma indireta, ou seja, não se obriga às Micro e Pequenas Empresas a cumprirem com o objetivo social, mas fomentando estas, teria de forma indireta a geração de empregos e distribuição de renda em locais distantes - não atingidos por grandes conglomerados. Presente então, no campo dos efeitos a conduta que caracteriza o fim extrafiscal do Simples Nacional. Neste ponto podemos descrever que tal medida - Simples Nacional - tem fenômeno secundário, de aplicação mediata, indireta em sentido impróprio, posto que não se trata de uma conduta que deve ser adotada pela Micro e Pequena Empresa, como disposto, mas sim, refletirá em um caso posterior.

Além disso, temos que aplicar no caso a proporcionalidade, no que tange ao controle de necessidade e de adequação, posto que, para que possa ser aplicada tal dispositivo, de exclusão das Micro e Pequenas Empresas, se faz necessário verificar se este ponto da Lei Complementar 123 de 2006, especificamente o artigo 17, inciso V, esta atingindo a finalidade da norma perante a Constituição Federal.

No caso do controle de adequação, podemos concluir que a medida de exclusão destas empresas no Simples Nacional, não se enquadram no que prevê e no que teve como finalidade a Constituição Federal de 1988, conforme demonstrado, demonstrando claramenteque tal norma é inválida, conforme descreveu Ávila ${ }^{53}$, onde quando não atingida o resultado almejado, tem-se que esta é inválida. E no presente caso, com a exclusão destas empresas, a norma não se tem o resultado, tendo em vista que estaria prejudicando ainda mais as empresas, e em muitos casos - se não na sua esmagadora maioria - estaríamos automaticamente fechando esta Micro e Pequenas Empresas, que na sua maioria já passa por dificuldades no seu dia-a-dia e quando se tem o aumento de tributos ${ }^{54}$, despesas, e ainda, dificuldades assessórias, temos a inviabilização desta empresas, não tendo assim, adequação com a finalidade constitucional de fomento desta empresas. 
Quanto ao controle de necessidade do dispositivo previsto no artigo 17, inciso $\mathrm{V}$, da Lei Complementar 123 de 2006, temos o conflito entre os princípios, tendo o Supremo Tribunal Federal decidido que atingiria a isonomia se deixasse que empresas com débito permanecessem no Simples Nacional, posto que, em tese, outras empresas de igual capacidade, estaria pagando e as demais empresas estariam no Simples sem estarem pagando.

Ocorre que, a questão fiscal arrecadatória dos tributos é diferente da questão extrafiscal não-arrecadatória. No caso, temos uma questão extrafiscal, que como já estudado, deve ter como finalidade a persecução de um objetivo maior, pautado por um meio, no caso o fiscal, não podendo o Estado ou o Judiciário pautar-se apenas na questão fiscal para se decidir a permanência destas empresas no Simples Nacional, devendo ser verificar outros princípios inerentes ao caso, como o princípio da proteção da empresa, o da função social da empresa, o da proporcionalidade, todos já citados, que embasaram o presente artigo.

Nas palavras de Ávila ${ }^{55}$ nos casos evidentes, teríamos a questão da nulidade do meio eleito pelo Poder Público, e acreditamos que trata-se de um caso evidente, onde o controle de necessidade deve ser exercido, juntamente com o controle de adequação, posto que, conforme demonstrado, nenhum, nem outro se enquadram no caso da exclusão das Micro e Pequenas Empresas.

\footnotetext{
${ }^{53}$ Ob. Cit.,2008, p.165.

${ }^{54}$ No caso do Simples Nacional, se tem uma diminuição tributária incidente sobre as empresas, e quando passa-se para o Lucro Presumido ou Lucro Real temos o aumento de carga de forma considerável, como exemplo, na atividade de consultoria, a carga passaria de aproximadamente $5 \%$, no Simples Nacional para aproximadamente $17 \%$, no Lucro Presumido.

${ }^{55}$ Ob. Cit., 2012, p.282.
} 


\section{REFERÊNCIAS BIBLIOGRÁFICAS}

AMARAL, Luiz Fernando de Camargo Prudente do. A função social da empresa no direito constitucional econômico brasileiro. São Paulo: SRS Editora, 2008.

ATALIBA, Geraldo. Sistema Constitucional Tributário Brasileiro. São Paulo: Revista dos Tribunais, 1966.

ÁVILA, Humberto. Teoria dos princípios: da definição à aplicação dos princípios jurídicos. $8^{\mathrm{a}}$ ed. São Paulo: Malheiros, 2008.

PAPADOPOL, Marcel. Fundamentos do Direito Tributário. Marcial Pons, São Paulo, 2012.

BARCELLOS, Ana Paula de. Ponderação racionalidade e atividade jurisprudencial. Rio de Janeiro: Renovar, 2005.

BARROS, Suzana de Toledo. O princípio da proporcionalidade e o controle de constitucionalidade das leis restritivas de direitos fundamentais. Brasília: Brasília jurídica, 2003.

BRASIL. Supremo Tribunal Federal. Recurso Extraordinário $n^{\circ}$ 627.543. Relator(a): Dias Tofolli. Acórdão em 29.10.2014, DJ 14.11.2013 (Ata nº 29) DJE 226. Disponível em: http://www.stf.jus.br. Acesso em: 13 de agosto de 2015.

CARVALHO, Paulo de Barros. Curso de Direito Tributário. 19 ed. São Paulo: Saraiva, 2007. CHAMBERLIN, E.H. The theory of monopolistic competition. Cambridge: Mass., 1933.COASE, R.H. The nature of the firm. In: WILLIAMSON, O. E e WINTER, S.G (Org.).The nature of the firm: origins, evolution, and development. Oxford: Oxford University Press, 1993.

COELHO, Fábio Ulhoa. Curso de Direito Comercial. 18ª Edição. São Paulo: Saraiva, 2014. V. 1.

COLLADO, Pedro Escribano. Legislacion administrativa: parte general. 19 ed. Universidad de Sevilla. Servicio de Publicaciones, 2003.

COMPARATO, Fábio Konder . Aspectos Jurídicos da Micro-Empresa. SAO PAULO: REVISTA DOS TRIBUNAIS, 1970. 
GALBRAITH, J. K. O Novo Estado Industrial. São Paulo: Abril Cultural, 1984.

GRAU, Eros. A ordem econômica na constituição de 1988. São Paulo: Malheiros, 1998. GOUVÊA, Marcus de Freitas. A extrafiscalidade no Direito Tributário. Belo Horizonte: Del Rey, 2006.

JUNIOR, Juntahy. Projeto de Lei Complementar: Regulamenta o parágrafo único do artigo 146 e o Inciso IX do art. 170 da Constituição Federal e da outras providências. Disponível em : http://www.camera.gov.br/sileg/integras/193056.pdf. Data de acesso: 23 de julho de 2015 .

LARENZ, Karl. Metodologia da ciência do direito. Lisboa: Fundação Calouste Gulbenkian, 1997.

MAIOR BORGES, Jorge Souto. <Pro-dogmática: por uma hierarquização dos princípios constitucionais>. Revista Trimestral de Direito Público, 1/146.

MAMEDE, Gladston. Direito empresarial brasileiro: teoria geral dos contratos. 1. Ed. São Paulo: Atlas. 2010, v.5.

MARSHALL, A. Princípios de economia: tratado introdutório. São Paulo: Abril, 1983.

NABAIS, José Casalta. O dever Fundamental de Pagar Impostos. Coimbra: Almedina, 2004.

NOVAIS, Jorge Reis. Direitos fundamentais: trunfos contra a maioria. Coimbra: Coimbra Ed., 2006.

PAPADOPOL, Marcel Davidman. A extrafiscalidade e os controles de proporcionalidade e de igualdade. Porto Alegre: Universidade do Rui Grande do Sul - UFRS, 2009.

PETTER, Lafayete Josué. Princípios constitucionais da ordem econômica: o significado e o alcance do art. 170 da constituição federal. São Paulo: RT, 2005.

PEREZ, Viviane. Função social da empresa: uma proposta de sistematização do conceito.2004. 
SHOUERI, Luis Eduardo. Normas Tributárias Indutoras e Intervenção no Domínio Econômico. Rio de Janeiro: Forense, 2005.

SILVA, José Afonso da. Curso de Direito Constitucional positivo. 31.ed. rev. e atual. São Paulo: Malheiros, 2008.

SRAFFA, P. The laws of returns under competitive conditions. Economic Journal, Dec. 1926. TOMAZETTE, Marlon. Curso de Direito Empresarial - Títulos de Crédito. Vol. 2, $3^{\text {a }}$ edição José Xavier Carvalho de Mendonça ; atualizado por Ricardo Rodrigues da Gama. Tratado de direito comercial brasileiro. Imprenta: Campina, SP, Russell, 2003.

WALRAS, M. E. L. Compêndio dos elementos de economia política pura. São Paulo: Abril, 1983. 